\title{
Cabaceiras, a "Roliúde Nordestina": efeitos do cinema nas atrações e nos produtos da oferta turística
}

\author{
Cabaceiras, the "Roliúde Nordestina": effects of film on attractions and products of tourism supply
}

Cabaceiras, la "Roliúde Nordestina": efectos del cine en las atracciones y productos de la oferta turística

\author{
Amada Gama Tavares ${ }^{1}$ \\ Valéria Araújo ${ }^{2}$ \\ Patrícia Whebber ${ }^{3}$
}

Este artigo foi recebido em 21 de MARÇO de 2019 e aprovado em 18 de NOVEMBRO de 2019

Resumo: Alguns filmes têm atraído pessoas às cidades usadas como cenários, a seus estúdios de produção ou a lugares que são ícones na cinematografia. O cinema, portanto, tem se consolidado como ferramenta de desenvolvimento turístico, levando cidades ao redor do mundo, usadas como locações fílmicas, a adaptarem sua oferta turística, criando produtos e atrações cinematográficas. No Brasil, entretanto, são poucos os exemplos de uma relação bem-sucedida entre turismo e cinema. Um dos mais significativos é a cidade de Cabaceiras, na Paraíba, conhecida como a "Roliúde Nordestina" por ter sido palco de mais de vinte produções. Considerando exemplos gerais e o caso específico de Cabaceiras, este artigo apresenta os efeitos do cinema no turismo a partir das possibilidades de criação de produtos e atrações turísticas. Para isso, o estudo teórico-exploratório-qualitativo usa revisão de literatura bibliográfica, além de análise de filmes e de páginas na Internet. A escolha do universo foi feita com a técnica de amostragem não-probabilística, por julgamento e conveniência. Os resultados apresentam ações realizadas em Cabaceiras, tendo como base o cinema, que visam, dentre outros objetivos, o incremento do turismo, tais como o letreiro à entrada da cidade, o Museu Cinematográfico e a sinalização de cenários. Em conclusão, percebe-se que as ações locais em Cabaceiras corroboram com o que autores têm sugerido para cidades-cenário desenvolverem o turismo cinematográfico e critica-se a forma de realização de algumas delas. Novos tópicos de pesquisa futura são sugeridos, dentro da temática abordada.

Palavras-chave: Cabaceiras/PB; Cinema; Produtos e atrações cinematográficas; Turismo.

\begin{abstract}
Some movies have attracted people to cities used as locations, to its production studios and also to icons sites of cinema. The film, therefore, has been consolidated as a tourist development tool. Film locations around the world have adapted its tourism offer, creating film products and attractions. In Brazil, however, there are few examples of successful relationships between tourism and film. One of the most significant is the city of Cabaceiras, in Paraíba, known as the "Roliúde Nordestina", once it was location of more than twenty productions. Considering general examples and the specific case of Cabaceiras, this paper presents the effects of film on tourism from the possibilities of products and attractions creations. For this, the theoretical and exploratory qualitative study uses review of literature and documents, and analysis pages on the Internet and movies. The choice of the universe was made with the non-probability sampling technique, by trial and convenience. The results show actions taken in Cabaceiras, based on the film, aimed, among other objectives, increase the tourism, as the sign at the entrance, the Museu Cinematográfico and the posting signs in scenarios.

\footnotetext{
1 Informações do autor:

Formação/curso: Mestre em Turismo. Instituição: Universidade Federal do Rio Grande do Norte - UFRN, Natal - RN, Brasil). E-mail: amada.tavares@hotmail.com

2 Informações do autor:

Formação/curso: Professora Doutora do Programa de Pós-Graduação em Turismo. Instituição: Universidade Federal do Rio Grande do Norte - UFRN, Natal - RN, Brasil). E-mail: valeriaaraujoufrn@gmail.com

3 Informações do autor:

Formação/curso: Professora Doutora do Programa de Pós-Graduação em Turismo. Instituição: Universidade Federal do Rio Grande do Norte - UFRN, Natal - RN, Brasil). E-mail: patriciawhebber.ufrn@ gmail.com
} 


\section{CABACEIRAS, A "ROLIÚDE NORDESTINA": EFEITOS DO CINEMA NAS ATRAÇÕES E NOS PRODUTOS DA OFERTA TURÍSTICA}

Amada Gama Tavares
Valéria Araújo

In conclusion, it is said that the actions corroborate what authors have suggested to city-scenario develop film tourism and critic the embodiment of some of them. It is suggest new topics for future research within the theme. Key words: Brazil; Cabaceiras; Film; Film products and attractions; Tourism.

Resumen: Algunas películas han atraído visitantes a ciudades usadas como escenarios, a sus estudios de producción y a lugares iconos de la cinematografía. El cine, por lo tanto, se ha consolidado como una herramienta de desarrollo turístico. Ciudades utilizadas como locaciones fílmicas han adaptado su oferta turística, creando productos y atracciones cinematográficas. En Brasil, sin embargo, hay pocos ejemplos de una relación exitosa entre turismo y cine. Uno de los más significativos es la ciudad de Cabaceiras/PB, conocida como la "Roliúde Nordestina", que fue escenario para más de veinte producciones. Teniendo en cuenta ejemplos generales y el caso de Cabaceiras, este artículo muestra los efectos del cine en el turismo a partir de las posibilidades de creación de productos y atracciones. Para ello, el estudio cualitativo, teórico y exploratorio usa la revisión de la literatura y de documentos, así como la análisis de películas y de páginas en Internet. La elección del universo se hizo con la técnica de muestreo no probabilístico, por ensayo y conveniencia. Los resultados muestran las medidas adoptadas en Cabaceiras, basadas en el cine, que pretenden, entre otros objetivos, el aumento del turismo, como el letrero de la entrada, el Museo del Cine y las señalizaciones en los escenarios. En conclusión, se dice que las acciones corroboran lo que los autores han sugerido para que las ciudades-escenarios desarrollaren el turismo inducido a través del cine y se hace críticas a la forma de realización de algunos de ellos. Se sugiere nuevos temas para investigaciones en el tema.

Palabras clave: Brasil; Cabaceiras; Cine; Productos y atracciones cinematográficas; Turismo.

\section{Introdução}

O impacto no desenvolvimento turístico de alguns locais, após serem usados como cenários para filmes, tem sido visível. É o caso da Nova Zelândia que, aproveitando a divulgação de suas paisagens por meio das trilogias O Senhor dos Anéis (2001, 2002 e 2003) e O Hobbit (2012, 2013 e 2014), aumentou significativamente o número de visitantes estrangeiros. Com isso, passou a desenvolver produtos turísticos relacionados aos filmes, tais como roteiros por lugares que foram de cenários e lançou-se no mercado turístico internacional como a "Home of Middle-earth". ${ }^{4}$ A região de Santa Bárbara, na Califórnia, de semelhante modo, depois do lançamento do filme Sideways - Entre Umas e Outras (2004), passou a usá-lo como ferramenta de marketing, além de ofertar roteiros e outros produtos turísticos, passando por significativo incremento no enoturismo, ${ }^{5}$ tema abordado no filme.

A partir daí, pode-se avistar uma relação entre turismo e cinema, mais especificamente numa relação de influência do segundo sobre o primeiro. Essa sinergia abrange alguns aspectos, tais como a formação da imagem do destino (CAMPO; BREA, 2010; CHAGAS; DANTAS, 2009; GUNN, 1988; SELLGREN, 2010), motivação para viagens (BEETON, 2005; EVANS, 1997; NASCIMENTO, 2009; SELLGREN, 2010), divulgação de destinos (DIAS, 2010; HUDSON; RITCHIE, 2006) e adequação e

\footnotetext{
${ }^{4}$ Nome da terra fictícia onde se passa a trama.

${ }^{5}$ Segmento cuja principal motivação da viagem é a degustação de vinhos, a visitação a viniculturas e o contato com tradições e cultura de localidades que produzem esta bebida.
}

Observatório de Inovação do Turismo - Revista Acadêmica

Vol. XIII, n 3, dezembro - 2019 
adaptação de uma cidade-cenário em relação à nova demanda, seja na oferta de produtos turísticos, seja na transformação do espaço, como tem sido o caso da Nova Zelândia.

Tais oportunidades têm levado alguns países a tomarem iniciativas para captação de produções audiovisuais. Alguns dos meios usados são políticas e incentivos fiscais e de órgãos, como é o caso das Film Commissions - órgãos públicos, privados ou mistos, que têm a função de fomentar e facilitar a produção e o desenvolvimento do audiovisual das regiões que representam.

Além disso, no momento pós-filme, também percebem-se algumas ações de incentivo ao desenvolvimento do turismo cinematográfico e ainda de pessoas que realizaram esse tipo de atividade. Os Estados Unidos, por exemplo, em 2004 lançaram uma campanha de marketing por meio da Visit America Alliance, com o seguinte slogan: "You've seen the movies, now see the set" (CONNELL, 2012; OXFORD ECONOMICS, 2010, p.48), convidando turistas a conhecerem lugares que foram cenários para filmes famosos. No Brasil, a revista Viagem e Turismo (2011) publicou a matéria Coisas de cinema - A paixão pelas telonas fez os leitores da VT rodarem o mundo em busca de lugares que serviram de locação para filmes, expondo relatos de turistas inspirados por filmes. Há, pois, tanto o esforço de campanhas publicitárias a incentivar visitas a cenários cinematográficos como o interesse de pessoas em vivenciar o que assistiram no cinema.

Beeton (2005) mostra que as atividades turísticas advindas desse contexto, incluem a visitação a locais onde foram filmados ou ambientados filmes e programas de TV, e ainda visitas a estúdios de produção e a parques temáticos relacionados ao audiovisual.

No Brasil, são poucos os exemplos de sucesso do turismo advindo da locação de produções cinematográficas. Pode-se supor que o processo de turistificação das favelas no Rio de Janeiro é uma forma de retorno de sua divulgação no cinema, por meio de filmes como Tropa de Elite (2007 e 2010) e Cidade de Deus (2002). Vilela (s/d) corrobora ao escrever que "[...]subir os morros onde ficam as favelas no Rio de Janeiro se tornou um aspirado atrativo turístico[...]", sob a influência desses dois filmes, "[...]que provocam o imaginário de uma realidade ao mesmo tempo perigosa e atraente". Em relação ao filme Cidade de Deus especificamente, ela diz: "Se, muitas vezes, a realização do filme foi questionada sobre o comprometimento que poderia causar no turismo na cidade, parece que o efeito foi contrário. Em vez de afastar o turismo, a exposição da violência tornou a cidade ainda mais atrativa”.

Isso foi constatado por Freire-Medeiros (2006, p.6), ao entrevistar agentes de turismo em favelas: "Todos os operadores com quem conversamos apontam o sucesso do filme Cidade de Deus como largamente responsável pelo crescente interesse pela favela como atração turística. Aclamado 
CABACEIRAS, A "ROLIÚDE NORDESTINA":

EFEITOS DO CINEMA NAS ATRAÇÕES E NOS PRODUTOS DA OFERTA TURÍSTICA
Amada Gama Tavares

Valéria Araújo

pela crítica internacional, o filme foi promovido mundo afora como um testemunho sobre a vida nos 'guetos' cariocas".

E há também o caso dos resultados da rodagem de mais de vinte produções audiovisuais em Cabaceiras, dentre as quais está O Auto da Compadecida (1999). Aproveitando tal potencial para locação de filmes, essa cidade do interior paraibano intitulou-se a "Roliúde Nordestina", criando ícones que têm servido como atrativos e produtos turísticos locais.

Tendo em vista tais cenários, semelhantes, mas diferentes, e relativamente recentes, este trabalho parte do questionamento de como a locação de filmes pode exercer influência turística em um lugar, no que diz respeito à criação de produtos e atrações turísticas. Objetiva, portanto, apresentar, tendo como base a cidade de Cabaceiras, na Paraíba, a influência do cinema no desenvolvimento de destinos turísticos a partir da apropriação de filmes pela formulação e oferta de produtos e atrativos turísticos relacionados ao cinema.

O trabalho inclui o marco teórico em levantamento bibliográfico a respeito da relação entre turismo e cinema, assim como de produtos e atrações turísticas cinematográficas, e os caminhos metodológicos adotados durante a pesquisa. Também trata, em seguida, especificamente do caso de Cabaceiras/PB e, por fim, traça algumas considerações a respeito da temática.

\section{Turismo e Cinema}

São várias as razões que impelem o homem a viajar, podendo depender da sociedade, da época e de motivações pessoais. Sobre isso, Santana (2009) destaca o papel de escritores e publicistas, que tornaram possível a formação de uma "mentalidade coletiva", criadora e propaladora de estereótipos e que, por sua vez, motivou deslocamentos para reconhecer o desconhecido, a diversidade das realidades humanas autênticas, exóticas e excêntricas aos olhos dos centros emissores de viajantes. $\mathrm{O}$ autor incumbe às obras Memórias de um turista, de Stendhal, e Viagens à minha terra, de Almeida Garrett, o desencadear da "peregrinação", dando origem no indivíduo ao gosto e à sede por conhecer lugares distantes de seu próprio ambiente, procurando autenticidades.

Os turistas buscam por oportunidades que lhes permitam viver experiências e sensações que alimentam (ou foram alimentadas) em seus sonhos e expectativas. É nesse sentido que Gastal (2005) corrobora com Santana e destaca o papel das mídias comunicacionais na transformação dos desejos em necessidade, por meio da exibição de produtos e lugares. O imaginário e os sentimentos acabam tornando-se elemento fundamental no consumo humano, inclusive no consumo de experiências turísticas. 


\section{CABACEIRAS, A "ROLIÚDE NORDESTINA": EFEITOS DO CINEMA NAS ATRAÇÕES E NOS PRODUTOS DA OFERTA TURÍSTICA}

Amada Gama Tavares

Valéria Araújo

Em outras palavras, os meios de comunicação podem despertar o desejo de conhecer lugares e culturas, podendo até transformar esse desejo em necessidade. Gera-se, assim, um fenômeno de "alimentação" do imaginário e dos desejos em relação ao turismo:

Os lugares são escolhidos para ser contemplados porque existe uma expectativa, sobretudo através dos devaneios e da fantasia, em relação a prazeres intensos, seja em escala diferente, seja envolvendo sentidos diferentes daqueles com que habitualmente nos deparamos. Tal expectativa é construída e mantida por uma variedade de práticas não-turísticas, tais como o cinema, a televisão, a literatura, as revistas, os discos e os vídeos, que constroem e reforçam o olhar [do turista] (URRY, 2001, p.18).

Então, de acordo com o autor, produções audiovisuais, por sua influência social, podem participar na formação de expectativas sobre lugares. Nos últimos anos, embora não seja um fenômeno novo, uma dessas manifestações audiovisuais tem se destacado em sua participação na atividade turística, a ponto de fazer surgir uma nova demanda no setor. Trata-se do cinema, que tem motivado milhares de pessoas a se deslocarem para visitar os cenários usados em produções fílmicas.

Em estudo sobre as sinergias entre turismo e cinema, o Ministério do Turismo do Brasil (2007, p.4) enfatiza que os filmes funcionam como "[...]difusores da cultura, das paisagens e dos valores sociais das regiões e mesmo dos países onde foram produzidos. Eles atuam no inconsciente coletivo, como uma propaganda subliminar, por meio das tramas ficcionais".

Na mesma linha de pensamento, o estudo Economic Contribution of the UK Film Industry destaca a relevância que os lugares têm em alguns filmes e suas possíveis consequências para o turismo:

Films not only generate interest in a country but also act to remind people about what the country has to offer - for example by showcasing scenery and the cultural offer. Indeed, just as product placement of cars, computers, jewellery and so on in films and television programmes has grown, it is not surprising that 'places' are also being featured in film on the same basis (OXFORD ECONOMICS, 2010, p.49).

O mesmo estudo afirma que um em cada dez turistas estrangeiros que visitam o Reino Unido o faz devido à exibição da localização em alguns filmes, tais como Harry Potter, Sherlock Holmes e Orgulho e Preconceito. 
Um dos aspectos mais relevantes em relação ao impacto de filmes em destinos turísticos diz respeito à longa vida útil de um filme, fazendo com que sua abrangência de espectadores confira a um destino um nível de notoriedade que os organismos responsáveis por sua promoção turística dificilmente conseguiriam atingir por outros meios (DIAS, 2010). Alguns filmes, tais como Manhattan (1979) e séries de TV como Sex and the City (1998), têm sido para a cidade de Nova Iorque um veículo de promoção turística, no mínimo, tão eficaz quanto anúncios publicitários, incrementando consideravelmente o setor.

Apesar de ser difícil mensurar o impacto do cinema sobre o turismo, alguns casos mostram dados relevantes, provando que o cinema pode dinamizar a atividade turística em locações fílmicas, especificamente pelo aumento do número de visitantes, conforme apresentado na tabela a seguir.

Tabela 1. Impactos do cinema no turismo

\begin{tabular}{|c|c|c|}
\hline Film or TV Series & Location & $\begin{array}{l}\text { Impact on Visitor Numbers } \\
\text { or Tourist Revenue }\end{array}$ \\
\hline Braveheart & Wallace Monument, Scotland & $\begin{array}{l}300 \% \text { increase in visitors year after } \\
\text { release }\end{array}$ \\
\hline Heartbeat & Goathland, North Yorkshire, England & $\begin{array}{l}\text { Three times the number of normal visitors } \\
\text { in } 1991\end{array}$ \\
\hline Deliverance & Rayburn County, Georgia & $\begin{array}{l}20,000 \text { film tourists a year Gross revenues } \\
\$ 2 \text { to } 3 \mathrm{~m}\end{array}$ \\
\hline Dances with Wolves & Fort Hayes, Kansas & $\begin{array}{l}25 \% \text { increase compared with } 7 \% \text { for } \\
\text { previous } 4 \text { years }\end{array}$ \\
\hline $\begin{array}{l}\text { Close Encounters of } \\
\text { the Third Kind }\end{array}$ & Devils Tower, Wyoming & $\begin{array}{l}75 \% \text { increase in } 197520 \% \text { visit now } \\
\text { because of the film }\end{array}$ \\
\hline Thelma and Louise & $\begin{array}{l}\text { Arches National Monument in Moab, } \\
\text { Utah }\end{array}$ & $19.1 \%$ increase in 1991 \\
\hline Field of Dreams & Iowa & $\begin{array}{l}35,000 \text { visits in } 1991 \text { Steady increase } \\
\text { every year }\end{array}$ \\
\hline Dallas & Southfork Ranch, Dallas & 5000,000 visitors per year \\
\hline The Lord of the Rings & New Zealand & $\begin{array}{l}10 \% \text { increase every year } 1998 \text { to } 2003 \\
\text { from UK }\end{array}$ \\
\hline Steel Magnolias & Louisiana & $48 \%$ increase year after release \\
\hline Last of the Mohicans & Chimney Rock Park, North Carolina & $25 \%$ increase year after release \\
\hline The Fugitive & Dillsboro, North Carolina & $11 \%$ increase year after release \\
\hline Little Women & Orchard House, Concord, Massachusetts & $65 \%$ increase year after release \\
\hline Bull Durham & Durham, Noth Carolina & $25 \%$ increase year after release \\
\hline Harry Potter & Various locations in U.K & $\begin{array}{l}\text { All locations saw an increase of } 50 \% \text { or } \\
\text { more }\end{array}$ \\
\hline Mission: Impossible 2 & National parks in Sydney & $200 \%$ increase in 2000 \\
\hline Gorillas in the Mist & Rwanda & $20 \%$ increase in 1998 \\
\hline Crocodile Dundee & Australia & $\begin{array}{l}20.5 \% \text { increase in U.S. visitors } 1981 \text { to } \\
1988\end{array}$ \\
\hline The Beach & Thailand & $22 \%$ increase in youth market in 2000 \\
\hline $\begin{array}{l}\text { All Creatures Great } \\
\text { and Small }\end{array}$ & Yorkshire Dales & Generated $£ 5 \mathrm{~m}$ for Yorkshire Dales \\
\hline
\end{tabular}

Observatório de Inovação do Turismo - Revista Acadêmica

Vol. XIII, $\mathrm{n}^{\circ}$ 3, dezembro - 2019 


\begin{tabular}{|c|c|c|}
\hline To the Manor Born & $\begin{array}{l}\text { Cricket St Thomas, Leisure Park, } \\
\text { England }\end{array}$ & $37 \%$ increase between 1978 to 1980 \\
\hline Middlemarch & Stamford, Lincolnshire, England & 27\% increase in 1994 \\
\hline $\begin{array}{l}\text { Four Weddings and a } \\
\text { Funeral }\end{array}$ & $\begin{array}{l}\text { The Crown HHotel, Amersham, } \\
\text { England }\end{array}$ & Fully booked for at least 3 years \\
\hline Mrs. Brown & Osborne House, Isle of Wight, U.K. & $25 \%$ increase \\
\hline Nothing Hill & Kenwood House, England & $10 \%$ increase in 1 month \\
\hline Saving Private Ryan & Normandy, France & 40 increase in American tourists \\
\hline Sense and Sensibility & Saltram House, England & $39 \&$ increase \\
\hline Pride and Prejudice & Lyme Park in Cheshire, UK & $150 \%$ increase in visitors \\
\hline Cheers & Location in Boston & $\begin{array}{l}\$ 7 \mathrm{~m} \text { in unpaid promotional advertising } \\
\text { each year }\end{array}$ \\
\hline Miami Vice & Miami & $\begin{array}{l}150 \% \text { increase in German visitors } 1985 \text { to } \\
1988\end{array}$ \\
\hline Forrest Gump & Savannah, Georgia & $7 \%$ increase in tourism \\
\hline Troy & Canakkale, Turkey & $73 \%$ increase in tourism \\
\hline $\begin{array}{l}\text { Captain Corelli's } \\
\text { Mandolin }\end{array}$ & Cephalonia, Greece & $50 \%$ increase over 3 years \\
\hline
\end{tabular}

Fonte: Hudson e Ritchie (2006, p.381)

Esses viajantes, motivados pelo que viram nas grandes telas, fizeram surgir um novo segmento no mercado turístico, o qual frequentemente tem sido chamado de film-induced tourism (BEETON, 2005; MACIONIS, 2004; O'CONNOR, 2011; RITTICHAINUWAT; RATTANAPHINANCHAI, 2015; SELLGREN, 2010). No entanto, também tem sido denominado de: film tourism (BUCHMANN, MOORE; FISHER, 2010; CONNELL, 2012; HUDSON; RITCHIE, 2006; KIM, 2012; TANSKANEN, 2012), turismo cinematográfico (CAMPO; BREA, 2010; LIMA, 2010; MINISTÉRIO DO TURISMO, 2007) e cineturismo (BUSBY; KLUG, 2001; NASCIMENTO, 2009; ROCHA; BRUSADIN, 2012).

Pode-se dizer que os destinos turísticos desta atividade são: localizações de filmagens de produções cinematográficas; lugares onde se desenrola a trama de um filme ou seriado; cidades onde há grandes estúdios cinematográficos; comunidades ligadas à vida de atores, produtores, roteiristas ou diretores; museus e outros (BEETON, 2005; CONNELL, 2012; HUDSON; RITCHIE, 2006; JEWELL; MCKINNON, 2008, NASCIMENTO, 2009; O'CONNER, 2010; SELLGREN, 2010).

Atentos a esse segmento e suas possibilidades, setores governamentais têm implantado políticas públicas e investido em ações para captação de filmes, a fim de inserir suas locações no mercado de audiovisuais. Há empenho para a criação e oferta de produtos específicos tanto por parte da iniciativa privada como da pública. A venda de roteiros turísticos, que incluem cenários 
cinematográficos, a publicação de movie maps ${ }^{6}$ o surgimento de agências especializadas e a criação de atrações, são alguns exemplos dessas ações, sugerindo a viabilidade de se oferecer serviços para o novo segmento (CAMPO; BREA, 2010; HUDSON; RITCHIE, 2006; O'CONNER, 2010).

\section{Atrações e produtos turísticos cinematográficos}

A primeira fase do desenvolvimento da indústria cinematográfica foi a do cinema mudo, quando ainda não se podia captar imagens e sons simultaneamente. Nesta fase, Inglaterra, EUA e França foram os países de destaque. Ainda nessa fase inicial, no começo da década de 1910, foi fundada Hollywood, nos Estados Unidos. Embora vários países europeus já tivessem avançado nessa arte, os monopólios norte-americanos fizeram pressão no setor e, por conta disso, em 1914, grandes ícones do cinema emigraram para Hollywood, num bairro da cidade de Los Angeles, Califórnia. Lá, a luminosidade natural era propícia às filmagens e o clima era melhor, pois chovia pouco, comparado ao clima europeu, além de que não se cobrava impostos. Durante a primeira guerra, o cinema europeu, em geral, estagnou, e Hollywood tomou a dianteira e foi aos poucos dominando o mercado mundial (PIROLI, 1965).

Muitos anos já decorreram desde a passagem do cinema mudo ao sonoro, com intensa evolução técnica. A transformação do imaginado em realidade tem utilizado cada vez mais ferramentas, tais como figurinos, linguagem, efeitos visuais e cenários. Esses últimos - os cenários -, dependendo do formato da cena, podem ser lugares fechados ou ao ar livre. A Organização Mundial do Turismo (2005), cumprindo seu papel de incentivadora do desenvolvimento turístico, diz que cidades podem proporcionar atraentes cenários para filmes, televisão e vídeos, especialmente quando elas são capazes de oferecer atraente patrimônio cultural ou construções de referência, tais como o Tate Modern com a Ponte do Milênio, em Londres, o Palácio Reichstag, em Berlim, ou o letreiro de Hollywood, na Califórnia.

Por mais que esteja mais em evidência somente nos últimos anos, a relação entre cinema e turismo não é recente, visto que, há muito tempo, várias cidades têm se fortificado como destinos turísticos como consequência de serem usadas como cenários em filmes. Algumas cidades, tais como Nova Iorque, Paris e Roma, conhecidas mundialmente, serviram de locação para famosas obras cinematográficas, tais como Manhattan (1979), O Código da Vinci (2006) e La Dolce Vita (1960), respectivamente.

${ }^{6}$ Mapas ou guias temáticos que apontam locações que se tornaram célebres após servirem de locação para filmes. 
A novidade, portanto, seria esta forma de divulgação ser aproveitada para fins turísticos, de forma mais direcionada, por meio, por exemplo, de incentivos para captação de filmes e criação de produtos e atrações turísticas pós-filme. A aplicação dessas estratégias tem ocorrido em nível nacional e regional.

A nível nacional, pode-se citar o exemplo da Nova Zelândia, que, após a captação da trilogia O Senhor dos Anéis, decidiu aproveitar a divulgação de suas paisagens, conseguindo aumentar consideravelmente o número de visitantes internacionais (BEETON, 2005; HUDSON; RITCHIE, 2006; SELLGREN, 2010). Uma das estratégias tomada pelo governo neozelandês para estimular o turismo e os investimentos estrangeiros foi a criação de uma posição em nível de gabinete: o Ministro de O Senhor dos Anéis, ${ }^{7}$ em 2001 (ano de estreia do primeiro filme). O cargo coube a Pete Hodgson, que também atuava como Ministro da Energia e da Ciência, Pesquisa e Tecnologia. Em artigo da Entertainment Weekly, ${ }^{8}$ Hodgson declara: "Este filme realmente nos colocará no mapa. Nem todo mundo soube que 'Star Wars' foi em Marrocos, mas todos saberão que a Terra Média é na Nova Zelândia". ${ }^{9}$ Fica clara, portanto, a decisão do país em promover-se turisticamente por meio do cinema.

Quanto a iniciativas a nível regional, há o exemplo das ações na região de Santa Bárbara, na Califórnia, após a filmagem do longa Sideways. A região elaborou roteiros turísticos cinematográficos e movie maps relacionados ao filme, que estreou em 2004. Segundo Magalhães (2005), em reportagem da Folha de São Paulo, as taxas de ocupação dos hotéis nunca foram tão altas até aquele ano, e as salas de degustação de vinhos registraram um aumento de até $40 \%$ no movimento (o enredo do filme está intimamente relacionado à fabricação de vinhos e ao enoturismo que ocorrem na região). $\mathrm{O}$ então porta-voz do escritório de turismo de Santa Bárbara, Shannon Turner Brooks, disse à Folha que o filme foi maravilhoso para a indústria de vinho, em geral, e que se esperava que outras regiões vinícolas do estado compartilhassem o sucesso e o aumento do enoturismo (MAGALHÃES, 2005).

A fim de atender a essa demanda, a região passou a ofertar novos produtos e atrações turísticas. A Santa Barbara Conference \& Visitors Bureau and Film Commission, por exemplo, relacionou turismo, vinho e cinema produzindo um movie map para visitas autoguiadas, contendo as locações do filme e elaborando roteiros turísticos cinematográficos, disponíveis para download, com os quais se pode planejar uma turnê de cinema personalizada por Santa Barbara. ${ }^{10}$

\footnotetext{
${ }^{7}$ Em termo original: "Minister of Lord of the Rings".

${ }^{8}$ Disponível em: http://www.ew.com/ew/article/0,,182977,00.html. Acesso em: 19 abr. 2018.

${ }^{9}$ Declaração original: "This film will really put us on the map. Not many people knew that 'Star Wars' was in Morocco, but everyone will know that Middle Earth is in New Zealand."

${ }^{10}$ Disponível em: https://santabarbaraca.com/itinerary/sideways-santa-barbara/. Acesso em 1 mar. 2019.
} 
Tanto de modo amplo, abrangendo países inteiros, como de modo local, abrangendo regiões, lugares usados como cenários e, posteriormente, visitados por turistas podem apresentar melhorias econômicas, além de se intensificar o fomento ao turismo, oferecendo a possibilidade de novas experiências (HUDSON; RITCHIE, 2006; NASCIMENTO, 2009). Uma das consequências desse fenômeno, como mencionado nos exemplos anteriores, tem sido a remodelação da oferta turística, negociando, junto aos detentores dos direitos autorais dos filmes, a criação de subprodutos de promoção de locações, a fim de capitalizar, de diferentes formas, com o turismo cinematográfico (CAMPO; BREA, 2010).

Os tipos de subprodutos são os mais variados, incluindo roteiros turísticos em locais usados como cenários ou em lugares que têm relação mais indireta com o cinema (BEETON, 2005; HUDSON; RITCHIE, 2006; JEWELL; MCKINNON, 2008; NASCIMENTO, 2009; RILEY; BAKER; VAN DOREN, 1998), como bairros onde moram atores famosos, como Hollywood, e ícones da cinematografia, como a Calçada da Fama.

Outra ação comum a locações fílmicas com visão turística, conforme destacam Hudson e Ritchie (2006), Sellgren (2010) e Tanskanen (2012), é a sinalização nos locais que foram usados como cenários. Dessa forma, agrega-se valor à experiência turística. Algumas vezes, o fato de ter sido usado como cenário é o atrativo principal do local, como é o caso do Cafe dês Deux Moulins, em Paris, um dos principais panos de fundo do filme O fabuloso destino de Amélie Poulain (2001) (Figura 1).

Intimamente relacionado à ação de sinalização está a de manutenção ou réplica de ícones, lugares, cenários e sets dos filmes, a fim de manter a autenticidade (HUDSON; RITCHIE, 2006). Dessa forma, os turistas podem ter acesso direto ao que foi usado no filme, e até mesmo recordações das filmagens. Quando uma cidade mantém ícones de produções fílmicas, ela acaba por criar uma marca que a identifica e a diferencia das demais: 


\section{Figura 1. Indicação do filme \\ O fabuloso destino de Amélie Poulain no Cafe dês Deus Moulins.}

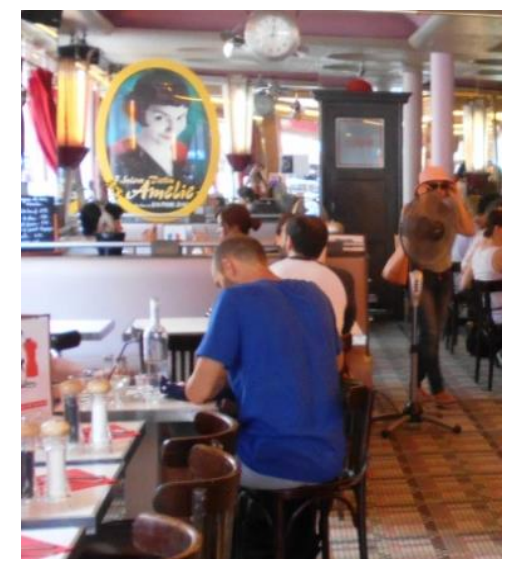

Fonte: Arquivo pessoal das autoras.

Branding a destination around a movie like this is quite common. The district of Hambleton in North Yorkshire, for example, branded itself Herriott Country, developing The World of James Herriott Museum following the success of All Creatures Great and Small. And Brontë Country in the United Kingdom still runs trade and press familiarization visits specifically based on the theme and its film and TV dramas (HUDSON e RITCHIE, 2006, p.391).

Além dessas estratégias, cita-se a criação de atrações turísticas cinematográficas, que consistem em ícones desenvolvidos após a filmagem de um ou vários filmes, tendo como objetivo atrair e entreter turistas (BEETON, 2005; HUDSON; RITCHIE, 2006). Por exemplo, as grandes produtoras de audiovisuais passaram a comercializar roteiros por seus sets de filmagem e estúdios cinematográficos. A Nova Zelândia, ao representar em tamanho gigante o personagem Gollum ( $O$ Senhor dos Anéis) no telhado do Aeroporto de Wellington, pode ser apresentada como exemplo na criação de ícones atrativos.

Todos esses produtos e atrações turísticas cinematográficas objetivam alcançar o tipo de turista mencionado por Urry (2001), ou seja, aquele que deseja reconhecer, reviver com o olhar, as imagens que foram antecipadas pela promoção turística, para incorporar seu desejo por autenticidade. Cabe, portanto, ao trade turístico usar de criatividade e inovação no desenvolvimento e oferta de seus produtos e na promoção dos mesmos, proporcionando novas sensações aos turistas.

No Brasil, há alguns poucos exemplos de destinos que têm usado essa oportunidade, aproveitando o fato de terem sido usados como cenários fílmicos para o incremento do turismo, pela criação de novos produtos e ícones turísticos. Um desses exemplos é a cidade do Nordeste Brasileiro 
de Cabaceiras, na Paraíba, que já foi palco de dezenas de produções e é denominada de "Roliúde Nordestina" (NASCIMENTO, 2009). Portanto, tendo como base o contexto teórico apresentado, este trabalho foca no caso de Cabaceiras, a fim de saber quais resultados o turismo tem apresentado a partir do cinema.

\section{Metodologia}

Seguindo a proposta de Demo (2000) sobre os gêneros de pesquisas, este estudo é teórico, por se dedicar a estudar teoricamente as relações entre cinema e turismo e suas implicações no desenvolvimento deste último. Em relação a seu objetivo, a pesquisa tem caráter exploratório, na medida em que visa a proporcionar mais informações sobre o assunto investigado, possibilitando, portanto, a definição e a delimitação do tema da pesquisa (PRODANOV; FREITAS, 2013). Sendo assim, envolve levantamento bibliográfico, análise de páginas na internet e de filmes, com o intuito de facilitar a compreensão da temática.

Ela tem ainda uma vertente de pesquisa descritiva, uma vez que são registrados e descritos os aspectos observados no caso de Cabaceiras (PB), sem que haja interferência neles, na busca por analisá-los (PRODANOV; FREITAS, 2013). Descreve, portanto, as relações existentes entre o cinema e a atividade turística, em termos gerais, e no município, especificamente. Quanto aos procedimentos técnicos, a pesquisa é bibliográfica (SILVA, 2004), realizada principalmente com base em livros, revistas, publicações em periódicos e artigos científicos, dissertações e teses, de forma que se teve contato com material já escrito sobre o assunto da pesquisa.

No que diz respeito à abordagem do problema, esse estudo tem abordagem qualitativa e consiste num estudo transversal único (GIL, 2002). Assim, retrata os elementos existentes na realidade da relação entre turismo e locação fílmica, a fim de analisá-los qualitativamente.

A respeito do universo, usou-se a técnica de amostragem não-probabilística, por julgamento $\mathrm{e}$ por conveniência, na medida em que foi selecionado o que se acredita ser a melhor amostra para a pesquisa em questão. Assim, tendo como fundamentação os traços teóricos apresentados, foi pesquisada uma localidade do Nordeste Brasileiro que tem servido de locação para produções cinematográficas, a saber, Cabaceiras, na Paraíba. A escolha dessa cidade justifica-se, pelo fato de que já foi palco de filmes brasileiros, tendo assim, a oportunidade de potencializar o turismo local a partir do cinema. 
CABACEIRAS, A "ROLIÚDE NORDESTINA":

EFEITOS DO CINEMA NAS ATRAÇÕES E NOS

PRODUTOS DA OFERTA TURÍSTICA
Amada Gama Tavares

Valéria Araújo

\section{Cabaceiras, a "Roliúde Nordestina"}

Situada no Nordeste Brasileiro, no interior do Estado da Paraíba, Cabaceiras é um município da região Cariri e fica a, aproximadamente, 180 quilômetros da capital João Pessoa, a partir da qual se tem acesso pelas rodovias BR 230/PB 148. Emancipada há pouco mais de 170 anos, foi-lhe atribuída pelo censo do Instituto Brasileiro de Geografia e Estatística, em 2010, uma população de 5.035 habitantes, com estimativas para 2018 de 5.503 habitantes. Esta população estaria distribuída numa área de $452,925 \mathrm{~km}^{2}$, resultando numa densidade demográfica de $11,12 \mathrm{hab} / \mathrm{km}^{2}$, segundo o mesmo censo. ${ }^{11}$

Com altitude aproximada de 390 metros, sua vegetação é formada por florestas subcaducifólica e caducifólica, características da região agreste, e seu clima é do tipo tropical chuvoso, com verão seco (CPRM, 2005). Tais fatores de clima e de vegetação concedem ao município uma das características mais típicas das regiões áridas do Nordeste. Além disso, destaca-se por ser o município de menor índice pluviométrico do Brasil, com apenas 250 mm/ano em média (ALVES; SOUZA; ARAÚJO, 2008). Outro aspecto natural próprio da cidade é o Lajedo do Pai Mateus, formação de rochas com cinco quilômetros de extensão, com coloração verde-amarelada, decorrente da presença de fungos, formando uma paisagem de belezas e peculiaridades (NÓBREGA et al., 2008).

Economicamente, a cidade encontra uma de suas principais bases na caprinocultura, a partir da qual desenvolve diversas atividades, tais como o artesanato em couro (ANDRADE, 2008) e a festa anual do Bode Rei. Este evento se destaca como fonte econômica da cidade, sendo instrumento também de valorização cultural e social (ALVES; SOUZA; ARAÚJO, 2008).

Nos últimos anos, devido à conservação de seus aspectos arquitetônicos, como sobrados construídos ainda no século passado (ANDRADE, 2008), assim como a suas características climáticas (baixo índice pluviométrico e luminosidade adequada aos trabalhos de filmagem) (PAPES; SOUSA, 2011), a locação de produções audiovisuais tornou-se também uma das atividades econômicas da cidade. Assim, Cabaceiras tem sido usada como cenário em diversas produções, incluindo longas, curtas e telenovelas.

Mais de vinte e cinco produções já foram locadas em Cabaceiras, sendo que a primeira data de 1924: A Ferração dos Bodes (PAPES; SOUSA, 2011). Outras produções rodadas na cidade foram Cinema, Aspirinas e Urubus (2005) de Marcelo Gomes, Canta Maria (2006) de Francisco Ramalho Jr., Romance (2008), de Guel Arraes, e cenas da novela Aquele Beijo, transmitida pela TV Globo entre 2011 e 2012 (ANDRADE, 2008; NÓBREGA et al., 2008).

${ }^{11}$ Disponível em: https://cidades.ibge.gov.br/brasil/pb/cabaceiras/panorama. Acesso em 1 mar. 2019. 
No entanto, uma das produções de mais sucesso foi o longa-metragem $O$ Auto da Compadecida (1999), também dirigido por Guel Arraes, que utilizou construções do centro para cenários importantes, como a igreja e a casa do padeiro, e também espaços nos arredores da cidade. Este filme é considerado, pelos cabaceirenses, como o que trouxe definitivamente o cinema para a cidade, colocando-a na rota do cinema nacional, de acordo com Nóbrega et al. (2008). Em entrevista a esses mesmos autores, Gilzane Castro, ex-diretora de Turismo de Cabaceiras, corroborou tal consideração ao dizer que "[...] esse filme foi um grande marketing para a cidade, inserindo-a no mundo dos filmes cinematográficos e também abrindo as portas para um turismo diferenciado que pode valorizar ainda mais a vocação cultural de Cabaceiras" (p.9). Estes relatos corroboram a relevância da longa vida útil de um filme, apontada por Dias (2010), o que expande o número de espectadores e, consequentemente, confere ao destino grande nível de notoriedade por tempo prolongado.

Diante desse potencial da cidade e de sua promoção em produções de audiovisual, divulgando os aspectos naturais e culturais singulares da região, percebe-se a existência das possibilidades esplanadas anteriormente neste trabalho e já executadas em vários países: a da relação entre cinema e turismo. Principalmente no que diz respeito à promoção do destino e à elaboração de novos produtos e serviços turísticos, aspectos destacados na teoria principalmente por Beeton (2005), Hudson e Ritchie (2006) e O'Conner (2010), que falam no desenvolvimento de meios, a partir do cinema, para atrair e entreter turistas. A cidade de Cabaceiras passou, portanto, a receber impactos no turismo por meio da atração de mais viajantes e da geração de impacto significativo na economia.

Em entrevista para o Portal de Notícias Polêmica Paraíba, o gestor cultural Wills Leal, figura importante na idealização de Cabaceiras como destino do cineturismo, afirmou que a cidade tem imagem positiva no imaginário dos brasileiros devido ao "[...]nosso cenário privilegiado para filmagens, assegurado por belezas naturais, como o Lajedo do Pai Mateus, muita luz e baixíssimo índice pluviométrico, o menor do Brasil". ${ }^{12}$

A semelhança climática com Hollywood, na Califórnia, fator que atraiu produtores para lá, e todos os outros fatores nomeados acima por Leal, levou à idealização do "Projeto Roliúde Nordestina" pela Prefeitura da cidade com apoio do Banco do Nordeste do Brasil, pela edição de 2007 do Programa BNB Cultura, e também do Ministério da Cultura e da empresa de energia SAELPA. A

12 Disponível em: http://www.polemicaparaiba.com.br/entretenimento/cabaceiras-roliude-nordestina-e-preferida-para-diretoresbrasileiros-10-filmes-rodados/. Acesso em 7 mar. 2019. 
ideia era buscar, numa visão mercadológica, meios para que a cidade tivesse estrutura adequada para gerar oportunidades benéficas por meio do cinema (ANDRADE, 2008; PAPES; SOUSA, 2011).

Um dos meios traçados foi a implantação de um centro para o estudo, preservação, exibição e fomento de produções cinematográficas e afins que, de alguma forma, tenham relação com a cidade (ANDRADE, 2008). Dentre as várias metas do projeto, uma delas era o incremento do turismo local. Por isso, o município buscou, dentre outras coisas, criar ícones cinematográficos, de forma que fossem característicos à cidade, possibilitando seu uso como atrativo turístico.

Neste aspecto, vê-se a cidade a pôr em prática o que Dias (2010) e Hudson e Ritchie (2006), por exemplo, traçaram em seus estudos em relação à divulgação de destinos a partir do cinema. $\mathrm{E}$ também o que outras experiências práticas externas vivenciaram no que diz respeito à adequação e adaptação da cidade a uma nova demanda, com a oferta de produtos turísticos e a transformação e sinalização de espaços.

Uma das principais atrações criadas na cidade em decorrência desse projeto é o vistoso letreiro com, aproximadamente, oitenta metros de comprimento por cinco de altura, com os dizeres: Roliúde Nordestina (NASCIMENTO, 2009) (Figura 2). Fazendo alusão, portanto, à Hollywood californiana, um dos maiores ícones cinematográficos mundiais, incentivando claramente a formação de uma identidade local. O letreiro foi posto logo no lançamento do projeto, em 2007, no alto de uma serra, podendo ser visto a uma distância de 1.800 metros, sendo o portal de entrada do município (PAPES; SOUSA, 2011). Desta forma, a cidade criou sua marca e fortaleceu sua identidade, relacionando-a diretamente ao mundo do cinema.

Figura 2. Letreiro da cidade de Cabaceiras/PB, em alusão ao de Hollywood, na Califórnia.

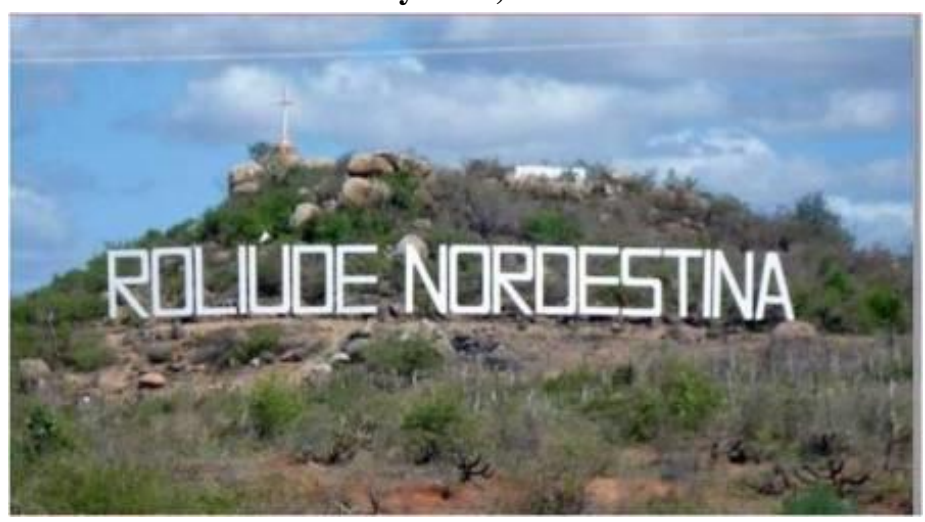

Arquivo pessoal das autoras. 
O letreiro se destaca como um dos principais ícones porque se transformou em referência da cidade, como elemento que diferencia e unifica a cidade diante das demais. Passou a fazer parte da identidade de Cabaceiras, aspecto essencial para destinos turísticos que buscam a diferenciação e destaque entre seus concorrentes. Nesse sentido, destaca-se o incremento de um local com relação cinematográfica para ser usado como atrativo turístico e como ícone da cidade, conforme foi dissertado por Beeton (2005).

Outra atração criada, a partir do projeto, foi o Memorial Cinematográfico, montado no antigo cinema da cidade, o Cine Ideal, que tem construção datada do século XIX (Figura 3). Esta ação da Prefeitura tem como um de seus objetivos a preservação de materiais que foram usados pelas produções na realização dos filmes, como também cópias dos filmes, roteiros, críticas, etc. (PAPES; SOUSA, 2011), corroborando com o que Hudson e Ritchie (2006) afirmam a respeito da manutenção de ícones do filme na cidade. Fotos das filmagens e trabalho da equipe de produção também são atrações do Memorial, conforme se vê na Figura 4, lembrança da filmagem de uma das cenas do sucesso baseado na obra de Ariano Suassuna. Na foto, é possível ver atores e outros participantes da equipe de produção. $\mathrm{O}$ memorial passa, portanto, a ser um instrumento que, além de servir à comunidade, resguarda seu patrimônio e é produto e atrativo turístico.

Figura 3.

Memorial Cinematográfico de Cabaceiras

Fonte: www.skyscrapercity.com Acesso em: 10 mar. 2019.

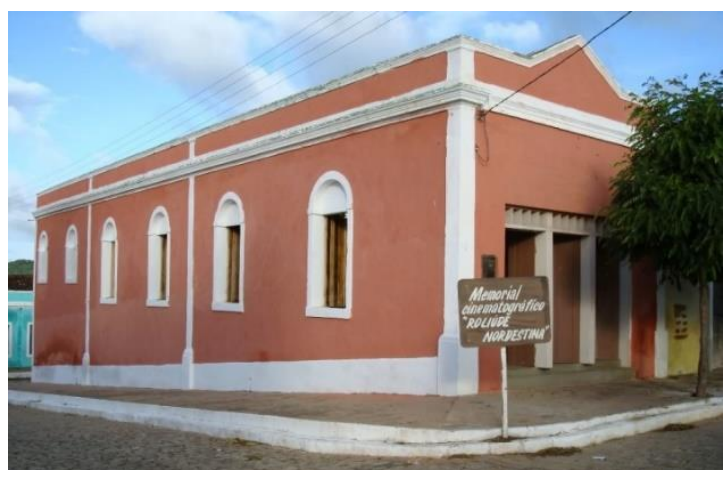

Fonte: www.skyscrapercity.com Acesso em: 10 mar. 2019.
Figura 4.

Elemento do Memorial Cinematográfico

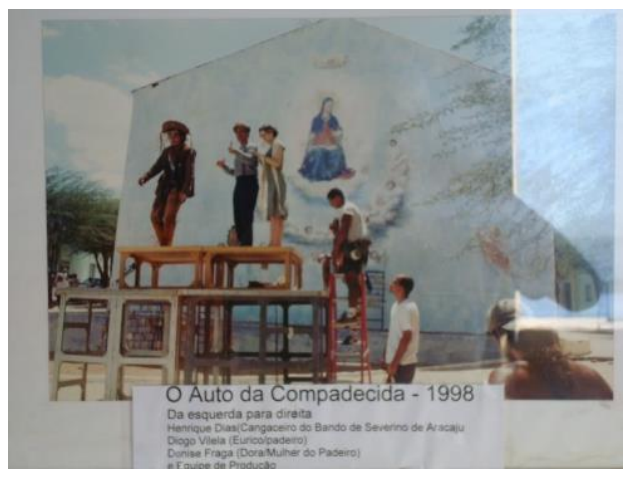

Fonte: www.skyscrapercity.com Acesso em: 10 mar. 2019

Observatório de Inovação do Turismo - Revista Acadêmica 
Destaca-se também a manutenção da pintura da imagem da Compadecida no prédio da Igreja Matriz de Nossa Senhora da Conceição (Figura 5), um dos símbolos mais significativos e memoráveis do filme $O$ Auto da Compadecida. Andrade (2008, p.5) afirma que a pintura é considerada símbolo e documento histórico na cultura de Cabaceiras, sendo "uma prova do passado", pois marca uma produção fílmica na história da cidade.

Figura 5. Pintura da imagem da

Compadecida na Igreja Matriz

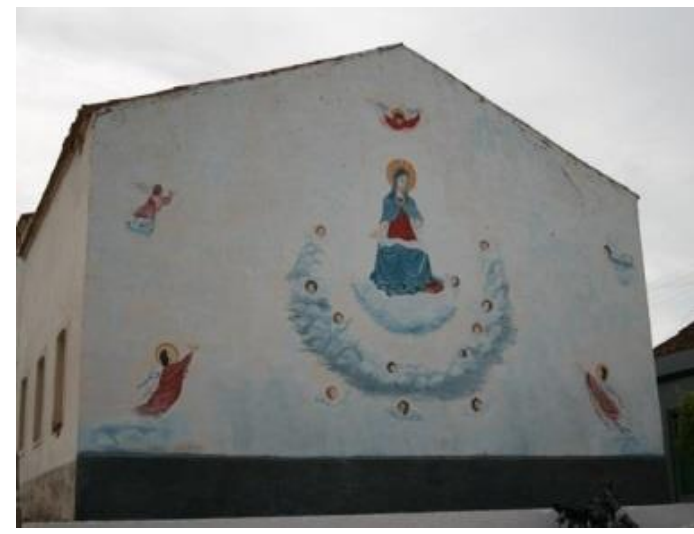

Fonte: www.domeuinterior.com.br. Acesso em: 10 mar. 2019.

Além disso, outras ações com viés turístico são possíveis de serem vistas como decorrentes da atividade cinematográfica, tais como as sinalizações dispostas pela cidade, indicando os locais que foram cenários de determinados filmes. É o caso, por exemplo, da casa usada como a casa do padeiro, em $O$ Auto da Compadecida (Figura 6). Ou ainda da sinalização no centro histórico, informando que o lugar foi cenário para os filmes O Auto da Compadecida (1999), Cinema, Aspirinas e Urubus (2003) e Canta Maria (2005) (Ver Figura 7). 


\section{CABACEIRAS, A "ROLIÚDE NORDESTINA": EFEITOS DO CINEMA NAS ATRAÇÕES E NOS PRODUTOS DA OFERTA TURÍSTICA}

\section{Figura 6. Sinalização do cenário da Casa do Padeiro}

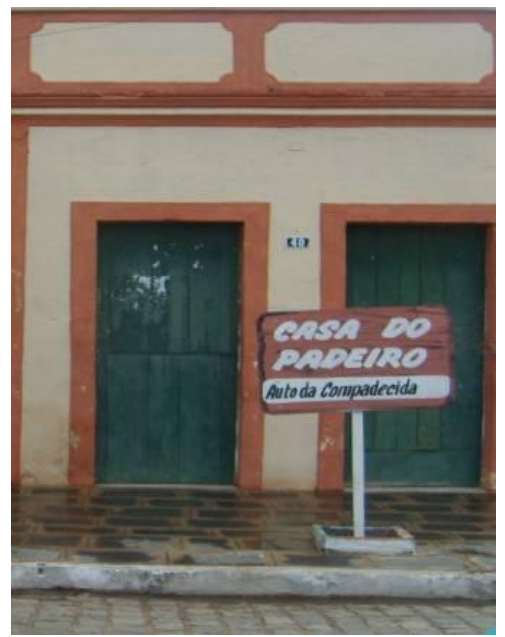

Fonte: Arquivo pessoal das autoras.
Amada Gama Tavares

Valéria Araújo
Figura 7. Sinalização do cenário no centro da cidade

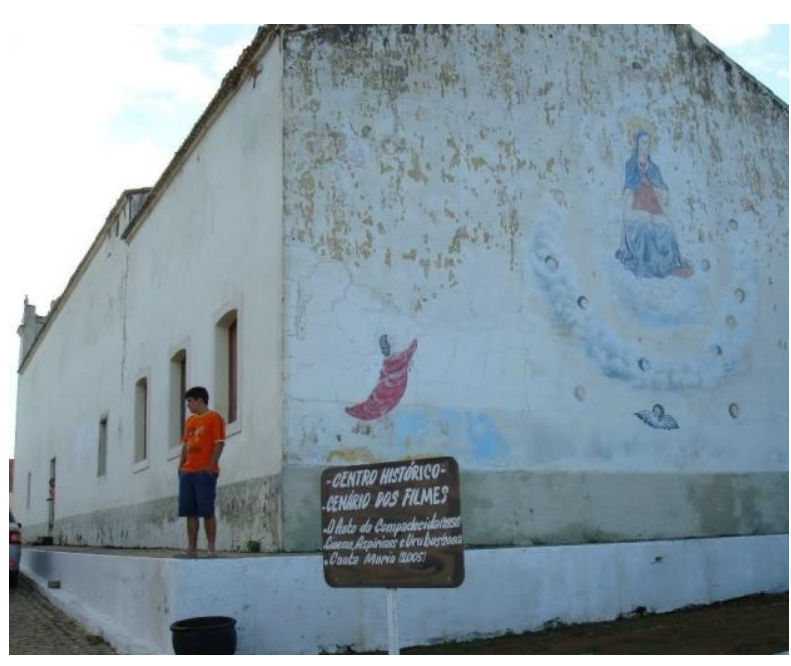

Fonte: Andrade (2008, p.3).

O cinema tem influenciado a criação de todas essas atrações e produtos turísticos, fortalecendo assim a identidade da cidade, que é apresentada ao restante do País. Nas diversas produções locadas em Cabaceiras, a cidade tem sido, em sua maioria, retratada como um espaço típico e representativo do sertão seco do Nordeste, do histórico cangaço, de belezas naturais e de destaques culturais. Desta forma, o cinema tem influenciado a formação da imagem da cidade, reafirmando as influências que o cinema pode exercer na atividade turística.

Em 2005, o então diretor do Departamento de Cultura do município declarou em entrevista que o cinema trouxe significativos benefícios socioeconômicos e culturais para a cidade, desde a filmagem do $O$ Auto da Compadecida. Ele destaca que a história, o artesanato e os recursos naturais da cidade foram divulgados, valorizando-os e fortalecendo a economia local (ANDRADE, 2008).

Ainda, segundo a autora, destaca-se que, após filmagens de audiovisuais, o município ganhou maior dinamicidade na geração de empregos, no comércio, em hotéis e em restaurantes, principalmente devido ao aumento do número de visitantes. Tal incremento econômico e turístico proporciona também maior visibilidade do município, facilitando o seu uso como cenário em outras produções.

Para a intensificação e máximo aproveitamento da relação entre turismo e cinema, o apoio governamental torna-se essencial. Em Cabaceiras, a prefeitura desempenhou seu papel arcando com a adaptação da cidade a cenários demandados pelas produções. Por exemplo, para a filmagem de $O$ Auto da Compadecida, o órgão providenciou a retirada de postes, o transporte para os figurantes, assim 
como outros apoios na constituição dos cenários (ANDRADE, 2008). Em momentos pós-filmes, as ações do governo municipal envolvem o projeto "Roliúde Nordestina", o Memorial Cinematográfico, as sinalizações, entre outros.

Cabaceiras, uma cidade pequena do interior do Nordeste, por ter o menor índice pluviométrico do país, algo não muito desejado por outras cidades, tornou-se um dos melhores locais para filmagens da região. Com a ajuda de outros aspectos naturais e culturais e do apoio governamental, a cidade tem se mostrado ao Brasil e ao mundo por meio das grandes telas do cinema. A partir daí, tem se fortalecido no imaginário da audiência, que se transforma em turistas, melhorando a economia local. Mas não somente isso, melhorando também a autoestima dos cabaceirenses, que agora podem dizer com orgulho que moram no lugar onde menos chove no Brasil.

\section{Considerações finais}

Partindo do atual contexto das sinergias entre turismo e cinema, já postas em prática por diversos países e cidades ao redor do mundo, vale-se investigar como lugares podem se apropriar da locação de filmes para incrementar o turismo. Inclusive com a criação de produtos e atrações turísticas relacionadas ao cinema, a fim de atender à demanda do turismo cinematográfico e impulsioná-la.

Este trabalho, ao apresentar como o cinema pode influenciar o turismo em cenários fílmicos, teve como foco o município de Cabaceiras, na Paraíba, que, pela importância do cinema para sua economia, se autodenominou a "Roliúde Nordestina".

A partir da apresentação do caso de Cabaceiras e sua relação com o turismo e o cinema, é possível perceber algumas semelhanças entre as ações tomadas na cidade e outros casos internacionais, assim com o que estudiosos dizem a respeito de produtos e atrações turísticocinematográficas. Algumas dessas semelhanças são: a criação de ícones capazes de formar ou fortalecer a imagem de uma cidade, o desenvolvimento de atrativos turísticos e a sinalização de locais usados como cenários.

Entende-se que a estrutura construída e ofertada pelo município ainda deixa a desejar, de forma que muitos aspectos poderiam ser maximizados. Por exemplo, as placas de sinalização poderiam ser deixadas de forma mais visível e com mais detalhes informacionais, e a pintura da imagem da Compadecida poderia ser renovada.

Por outro lado, é compreensível que um dos aspectos da imagem de Cabaceiras passada, na maioria dos filmes ali locados, é sua rusticidade e simplicidade do povo nordestino. Sendo, portanto, 
relevante a manutenção dessa característica, para a compatibilidade da imagem propagada e a realidade local. No entanto, destaca-se que rústico não é sinônimo de precariedade ou de mal cuidado.

Além disso, durante o processo de apropriação do cinema pela atividade turística, cabe atentar também para os possíveis impactos negativos. Sobre isso, Andrade (2008) destaca que as exigências do enredo de alguns filmes podem alterar a arquitetura de prédios da cidade, danificando a preservação e manutenção do patrimônio, como ocorreu durante a produção de $O$ Auto da Compadecida, que modificou a Igreja Matriz e algumas casas.

As mudanças, além dos aspectos físicos da cidade, ou seja, sociais e culturais, também devem ser alvos de atenção. No caso de Cabaceiras, que era conhecida por ser uma das cidades com menor índice pluviométrico do País, passou a ser a cidade conhecida nacionalmente por ser cenário de filmes de sucesso, sobressaindo-se como a "Roliúde Nordestina". Obviamente, isso resultou em mudanças na economia, nas relações sociais e na valorização cultural do município. Vale, então, analisar se essas mudanças estão ocorrendo, de maneira benéfica, para todos os envolvidos.

Tais pontos devem estar sempre em discussão, de forma que não se permita que os impactos negativos se sobressaiam diante dos positivos. E ainda, de maneira que o número de beneficiados com a produção fílmica seja o mais abrangente possível.

Por mais que a cidade já tenha agido de algumas formas para criar produtos e atrações turísticos, é notável a oportunidade de desenvolvimento de uma oferta mais diversificada, como a criação de roteiros turísticos cinematográficos, envolvendo locais e ações relacionadas a filmes e à vida de atores e diretores. Poder-se-ia ainda elaborar um movie map da cidade, tomando como exemplo os diversos casos internacionais, e sendo pioneira na oferta desse produto no Brasil.

Cidades e países turísticos usam símbolos para formar sua identidade e lançar-se no mercado. Cabaceiras, além do sertão, da festa do Bode Rei e do Lajedo do Pai Mateus, tem o cinema como símbolo, tendo como principal ícone o letreiro em moldes do de Hollywood. Para fortalecimento turístico e de desenvolvimento de projetos, cabem futuras pesquisas mais específicas sobre assuntos, tais como resultados econômicos advindos do uso da cidade como cenário fílmico; implicações sociais causadas pelas produções; impactos turísticos após filmagens e divulgação e; formas de se aproveitar o uso como cenário fílmico para a promoção turística da cidade.

\section{Referências}

ALVES, J. J. A.; SOUZA, E. N.; ARAÚJO, M. A. Estudo descritivo da tipologia turística do município de Cabaceiras - Paraíba. Caderno Virtual de Turismo, v. 8, n. ${ }^{\circ}$ 3, p. 86-103, 2008. 
ANDRADE, V. G. de. Traços de modernidade? A invenção da História e da cultura em Cabaceiras. In: Anais Encontro Estadual da ANPUH, 13. 2008, Guarabira (PB), Brasil. História e Historiografia: entre o nacional e o regional. João Pessoa: Editora Universitária, 2008, p. 10.

BEETON, S. Film-induced Tourism. Clevedon: Channel View Publications, 2005.

BUCHMANN, A.; MOORE, K.; FISHER, D. Experiencing film tourism: authenticity \& fellowship. Annals of Tourism Research, v. 37, n. ${ }^{\circ}$ 1, p. 229-248, jan. 2010.

BUSBY, G.; KLUG, J. Movie-induced tourism: the challenge of measurement and other issues. Journal of Vacation Marketing, v. 7, n. ${ }^{\circ}$ 4, p. 316-332, out. 2001.

CAMPO, M. L. R.; BREA, J. A. F. Conceptualización del turismo inducido a través del cine: una aplicación al mercado español. Percursos \& Ideas: Revista Científica do ISCET. n. ${ }^{\circ} 2,2^{\text {a }}$ série $^{2}$ (on-line), p. 91-98, 2010.

CHAGAS, M. M. das; DANTAS, A. V. S. A imagem do Brasil como destino turístico nos websites das operadoras de turismo europeias. Revista Acadêmica Observatório de Inovação do Turismo, v. 4, n. ${ }^{\circ}$ 2, p. 1-19, jun. 2009.

CONNELL, J. Film tourism: evolution, progress and prospects. Tourism Management, v. 33, n. ${ }^{\circ}$ 5, p. 1007-1029, out. 2012.

CPRM - Serviço Geológico do Brasil. Projeto cadastro de fontes de abastecimento por água subterrânea. Diagnóstico do município de Cabaceiras, estado da Paraíba, Recife: CPRM/PRODEEM, 2005.

DEMO, P. Metodologia do conhecimento científico. São Paulo: Atlas, 2000.

DIAS, F. A promoção de destinos turísticos através do cinema: a via mais eficaz. In: Conferencia Internacional de Turismo e Cinema, 1, 2010, Instituto Politécnico de Leiria e GITUR Grupo de Investigação em Turismo, p. 7-14, 2010.

EVANS, M. Plugging into TV tourism. Insights, p. 35-38, mar. 1997. London: English Tourist Board.

FREIRE-MEDEIROS, Bianca. A construção da favela carioca como destino turístico. Rio de

Janeiro: $\quad 2006 . \quad$ Disponível em:

http://bibliotecadigital.fgv.br/dspace/handle/10438/4138. Acesso em 28 de fevereiro de 2019.

GASTAL, S. Turismo, imagens e imaginários. São Paulo: Aleph, 2005.

GIL, A. C. Como elaborar projetos de pesquisa. 4.ed. São Paulo: Atlas, 2002.

GUNN, C. Vacationscapes: designing tourist regions. New York: Van Nostrand Reinhold, 1988.

HUDSON, S.; RITCHIE, J. R. B. Promoting destinations via film tourism: an empirical identification of supporting marketing initiatives. Journal of Travel Research, v. 44, p. 387-396, maio, 2006.

JEWELL, B.; MCKINNON, S. Movie Tourism: a new form of cultural landscape? Journal of Travel \& Tourism Marketing, v. 24, n. ${ }^{\circ}$ 2, p. 153-162, 2008.

KIM, S. Audience involvement and film tourism experiences: Emotional places, emotional experiences. Tourism Management, v. 33, n. ${ }^{\circ}$ 2, p. 387-396, abr. 2012. 
LIMA, L. B. El turismo cinematográfico desde una mirada antropológica: las negociaciones de identidades en los escenarios de películas. In: Seminário da Associação Nacional Pesquisa e Pós-Graduação em Turismo, 7. Universidade Anhembi Morumbi, São Paulo (SP), 2010. Disponível em: https://www.anptur.org.br/anais/anais/files/7/62.pdf. Acesso em 9 jun.2018.

MACIONIS, N. Understanding the Film-Induced Tourist. In: FROST, W.; CROY, G.; BEETON, S. (editores). International Tourism and Media Conference Proceedings. Melbourne: Tourism Research Unit, Monash University, 2004, p. 86-97. Disponível em: http://www.researchgate.net/publication/228790015_Understanding_the_film-induced_tourist. Acesso em: 10 jun. 2018.

MAGAlHÃES, M. 'Sideways' desvia rota da uva na Califórnia. Folha de São Paulo Online, São Paulo, 10 mar. 2004. Folha Turismo. Disponível em: http://www1.folha.uol.com.br/folha/turismo/noticias/ult338u4940.shtml. Acesso em: $20 \mathrm{dez}$. 2018.

MINISTÉRIO DO TURISMO. Estudo de Sinergia e Desenvolvimento entre as Indústrias do Turismo e Audiovisual Brasileira. Brasília: Instituto DHARMA; Ministério do Turismo, 2007.

NASCIMENTO, F. M. e. Cineturismo. São Paulo: Aleph, 2009.

NÓBREGA, D. L.; SANTOS, F. A.; SOUZA, R. R. B. de; PEREIRA, R. de C. de F. Significados e aspectos simbólicos da imagem mercadológica de Cabaceiras/PB como "Roliúde Nordestina". In: Encontro de Estudos Organizacionais da ANPAD, 5. 2008. Belo Horizonte (MG), Brasil, 2008. Disponível em: http://www.anpad.org.br/admin/pdf/EnEO520.pdf. Acesso em: 21 nov. 2019.

O'CONNOR, N. A conceptual examination of the film induced tourism phenomenon in Ireland.

European Journal of Tourism, Hospitality and Recreation, 2011, v. 2, n. ${ }^{\circ}$ 3, p.105-125. Instituto Politécnico de Leiria, impresso em Portugal.

ORGANIZAÇÃO MUNDIAL DO TURISMO. City Tourism \& Culture: The European Experience. A Report produced for the Research Group of the European Travel Commission (ETC) and for the World Tourism Organization (UNWTO) by LAgroup \& InterartsBrussels. Madrid, 2005. Disponível em: http://www.unwto.org/. Acesso em: 19 dez. 2018.

OXFORD ECONOMICS. The Economic Impact of the UK Film Industry. $3^{a}$.ed, 2010. Disponível em: http://industry.bfi.org.uk/media/pdf/i/r/. Acesso em: 29 dez. 2018. 
PAPES, A. C.; SOUSA, J. M. de. Cabaceiras: a Cidade Turística no Cariri da Paraíba. Informe Gepec, Toledo, v. 15, n. ${ }^{\circ}$ 2, p. 118-133, jul./dez. 2011.

PIROLI, S. Noções de Cinema. São Paulo: F.T.D, 1965.

PRODANOV, C. C.; FREITAS, E. César de. Metodologia do trabalho científico: métodos e técnicas da pesquisa e do trabalho acadêmico. 2. ed. Novo Hamburgo: Feevale, 2013.

RILEY, R.; BAKER, D.; VAN DOREN, C. S. Movie induced tourism. Annals of Tourism Research, v. 25, n. ${ }^{\circ}$ 4, p. 919-935, 1998.

RITTICHAINUWAT, B.; RATTANAPHINANCHAI, S. Applying a mixed method of quantitative and qualitative design in explaining the travel motivation of film tourists in visiting a filmshooting destination. Tourism Management, v. 46, p. 136-147, fev. 2015.

ROCHA, G. de A. P.; BRUSADIN, L. B. Pós-modernidade e convergência cultural: o caso do Cineturismo. In: Anais Congresso de Ciências da Comunicação na Região Sudeste, 17, 2012, Ouro Preto (MG), Brasil. Intercom, 2012, p. 1-15. Disponível em: http://www.intercom.org.br/PAPERS/REGIONAIS/SUDESTE2012/resumos/R33-0481-1.pdf. Acesso em 16 jul. 2018.

SANTANA, A. Antropologia do Turismo: analogias, encontros e relações. São Paulo, SP: Aleph, 2009.

SELLGREN, E. Film-induced tourism: The effect films have on destination image formation, motivation and travel behavior. Copenhagen Business School, 2010.

SILVA, C. R.; O. Metodologia do trabalho científico. Fortaleza: Centro Federal de Educação Tecnológica do Ceará, 2004.

TANSKANEN, T. Film tourism: study on how films can be used to promote tourism. Laure University of Applied Sciences, 2012.

URRY, J. O olhar do turista: lazer e viagens nas sociedades contemporâneas. São Paulo: Studio Nobel: SESC, 2001.

VIAGEM E TURISMO. Ano 17, n. ${ }^{\circ}$ 1, edição 183, p. 26-27, jan. 2011. Editora Abril.

VILELA, L. Passeio nas favelas: a influência do cinema no imaginário turístico. Interartive, (s/d). Disponível em: https://interartive.org/2009/08/turismofavela. Acesso em 28 fev. 2019. 